\title{
Development of Brazil nut oil microemulsion as vehicle for Levamisole
}

\author{
Pricila Castilho Gustmann ${ }^{\mathrm{a}}$, Aron Carlos de Melo Cotrim ${ }^{\mathrm{b}}$, Evaldo Martins Pires ${ }^{\mathrm{c}}$, Carla Regina Andrighetti ${ }^{\mathrm{d}}$, \\ Dênia Mendes Sousa Valladão ${ }^{\mathrm{d}}$, Elton Brito Ribeiro ${ }^{\mathrm{d} *}$ \\ ${ }^{a}$ Graduated in Pharmacy - Federal University of Mato Grosso, campus of Sinop -MT, 78550-356, Brazil. \\ ${ }^{\mathrm{b}}$ Post Graduated in Biochemistry \& Molecular Biology - Federal University of Mato Grosso do Sul, Campo Grande-MS, 79070-900, Brazil. \\ ${ }^{c}$ Institute of Natural, Human and Social Sciences, Federal University of Mato Grosso,campus of Sinop-MT, 78550-356, Brazil. \\ ${ }^{\mathrm{d} I n s t i t u t e}$ of Health Sciences, Federal University of Mato Grosso, campus of Sinop-MT, 78550-356, Brazil.
}

\section{ARTICLE INFO}

Article history:

Received on: 15/03/2017

Accepted on: 20/05/2017

Available online: 30/08/2017

Key words:

Bertholletia excelsa $\mathrm{H}$. B. K.; Microemulsion; Stability

study; Levamisole.

\begin{abstract}
Brazil nut (Bertholletia excelsa H. B. K.) is one of the most valuable national Lecythidaceae from Brazil, collaborating with local economy. Besides being rich in nutrients, it has high content of unsaturated fatty acids, proteins and vitamins. On the other hand, levamisole (LMS) is a synthetic imidazothiazole derivative mostly used as agent in anthelmintic treatment; however it is reported to have issues in its oral bioavailability. Microemulsion (ME), immiscible liquids stabilized by surfactants, is a promising bioavailability enhancer nowadays by modifying the release of active ingredient at its site of action, reducing therapeutic dosage with consequent side effects, and increasing absorption of natural ingredients. So, the development of a stable ME containing Brazil nut oil to carry LMS can be a promising pharmaceutical form in this drug therapeutic efficiency behalf. For that, it was developed a stable oil-in-water ME which held $\mathrm{pH}$, conductivity, and refractive index along the study, presenting satisfactory stability under long-term stress conditions. Its particle size is classified as nanostructure $(33,35 \mathrm{~nm})$, and rheological parameters confirmed a Newtonian behavior, with constant viscosity. The Brazil nut oil ME can be an alternative as adjuvant in pharmaceutical forms and a promising upgrading tool to carry LMS, improving its therapy.
\end{abstract}

\section{INTRODUCTION}

The development of drug delivery vehicle has increased in recent years (Ansari et al., 2012; Ribeiro et al., 2016). The poor bioavailability is a common issue in drug development, which implies in more frequent drug administrations to reach the effect, and blood level fluctuations due to poor drug release pattern. Such issues lead to sub dosage or toxicity, among several other disadvantages implying to an inefficient pharmacologic therapy (Pezzini et al., 2007). An alternative to minimize such risks and improve drug therapy is by utilizing pharmaceutical systems that modify the drug kinetics, and increase the amount of active pharmaceutical ingredient (API)available in the organism, delivering at its site of action in a regulated speed (Hu et al., 2008; Hafner et al., 2014). Many of such products have demonstrated to be able to improve treatment of diseases or stimulate the immune system, and for that immunomodulatory

* Corresponding Author

Email: ribeiroufmt@ hotmail.com molecules delivered by colloidal systems have been an interesting strategy according to literature (Pessoa et al., 2014). Microemulsion (ME) is a quite recent system in that approach. ME have become a promising bioavailability enhancer. For that, immiscible liquids are stabilized by surfactants, reducing their surface tension, emulsifying, dispersing and solubilizing solutes, combining the active ingredient in one of the phases (Acharya and Hartley, 2012; Lawrence and Rees, 2012; Ribeiro et al., 2015). Its benefits include increased API solubility, minimized degradation processes such as thermal and photo degradation, gastric resistance, controlled release of active ingredient, reduction of therapeutic dosage and consequent side effects, improving the adherence to treatment which leads to a significant improvement of a known therapy (Kesarwani and Gupta, 2013). Nanostructures, such as ME, might be able also to increase the absorption of natural ingredients, delivering the active ingredient at the desired site of action in modulated doses (Bonifácio et al., 2014). Conversely, medicinal plants and their extracts have great relevance as source of active ingredients and adjuvants in the pharmaceutical field (Pessoa et al., 2014). 
The Brazil nut-fruit (Bertholletia excelsa H. B. K.) is one of the more invaluable national species in Brazil, holding importance as source of nutrients (minerals, proteins and lipids), and their growth collaborates to the economy, especially in Amazon region (Ferreira et al., 2006; Gonçalves et al., 2009).

The oil is commonly obtained by cold pressing the Brazil nut seeds, presenting itself as yellowish and with lightly sweet taste and smell (Kluczkovski et al., 2015). Its composition is mostly unsaturated fatty acids, monounsaturated oleic fatty acid (36.21 to $51 \%$ ) and oleic fatty acid (34 to $38.28 \%$ ). Although oleic fatty acid is the main component of the almond oil, Brazil nut is also a great source of polyunsaturated fatty acids and protein, such as excelsina, selenium and sulfured amino acids forming high bioavailability complexes, and vitamins $\mathrm{A}, \mathrm{B}, \mathrm{C}$, and $\mathrm{E}$, the last one with antioxidant and immune system activity (Ferreira et al., 2006; Silva et al., 2010; Santos et al., 2011; Kluczkovski et al., 2015).Although several studies have taken place about the properties of this plant and its products, the use of Brazil nut in the pharmaceutical field as an adjuvant has not yet been elucidated.

The vehicles with vegetable oils are a viable option to the development of nanostructured systems as an alternative to drug vehicle (Chaud et al., 2014; Pessoa et al., 2014; Lanes et al., 2016). Levamisole (LMS) is a synthetic imidazothiazole derivative, and has been used as antirheumatic drug in 1970s and for colon cancer treatment with 5-fluorouracil in 1990s (Figure 1). Currently, it is mostly used as anthelmintic agent by paralyzing worm's muscles (Ribeiro et al.,2015). Besides, some authors have considered LMS as a bio pharmaceutics III in drug classification, indicating that due to permeability issues its oral bioavailability can be diminished (Shaji and Jadhav 2010), which calls attention to the possibility of improvement when combined in other systems, as ME.

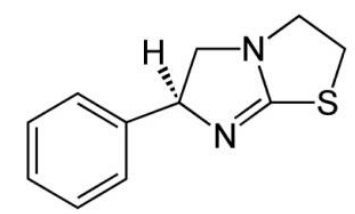

Fig. 1: Chemical structure of LMS.

Therefore, the use of LMS has decreased in last years for its side effects when administered as a regular pharmaceutical form (tablets), and the promising composition of ME system can improve LMS bioavailability or allow its injectable application.

In this circumstances, the aim of this work was to develop a stable ME formulation containing Brazil nut oil to accommodate LMS, as well as, to establish the parameters of characterization and stability that allow its further use in a pharmaceutical form.

\section{MATERIAL AND METHODS}

\section{System composition}

The ME systems were formulated with Brazil nut oil; distilled water; Sorbitan Monostearate (SP - Span 80 ${ }^{\circledR}$ ), HLB =
4,3; Polysorbate 80 (TW - Tween $80^{\circledR}$ ), HLB = 15,0; and 1Butanol (BT). The Brazil nut oil was provided by the Quality Control Laboratory of University of Mato Grosso, Campus of Sinop, LMS hydrochloride (declared content of 99,0\%) was purchased from Henrifarma ${ }^{\circledR}$, Brazil, and the other reagents were acquired from Sigma $^{\circledR}$, USA.

\section{Surfactant Mixing Ratio}

The co-surfactant (BT) was used in a ratio equivalent to $10 \%(\mathrm{Fc}=1)$ of the surfactant mixture. The HLB of the surfactant mixture (SP and TW) and the composition required to achieve an HLB corresponding to the oily phase were calculated (Ribeiro et al., 2015).

\section{Microemulsion Systems Development}

The process was performed through the following steps: (1) the proportion of oily phase, aqueous phase, and surfactant mixture runs from 10 to $80 \%$ of the formulation, following to mechanic homogenization; (2) the construction of pseudoternary diagrams comprising points representing each proportion of components; (3) the formulations were individually classified, 24 hours later, as ME, gelemulsion (GE), or phase separation (PS); (4) the determination of each region was defined by performing aqueous titration with the ratio of oil/surfactants phase running from 1:9 up to 9:1. Adding distilled water in quantities between $0.05 \mathrm{~mL}$ and $0.20 \mathrm{~mL}$ performed the titration. During this process, the mixture was agitated manually and mechanically. After homogenization the formulations were visually classified. Diagrams to define the composition of each type of formulation were constructed from data attained using Sigma Plot 8.0 software. After pseudoternary diagram acquisition, compositions of the systems that fell into the ME region were defined. This region containing pre-selected points was distributed in lines, dividing the region due to achieve representative samples for the LMS incorporation, which were later characterized and submitted to stability studies.

\section{Drug Incorporation in the Microemulsion}

LMS incorporation in the ME samples was performed by adding its equivalent weight to the aqueous phase in distilled water, under agitation, followed by surfactant and Brazil nut oil addition, respectively. The systems were made to provide $50 \mathrm{mg}$ of LMS every $95 \mathrm{~mL}$ of ME, based on the apparent average density points of the system.

\section{Physicochemical Characterization}

Physicochemical parameters of the formulations were measured through centrifugation, $\mathrm{pH}$, electrical conductivity and refractive index. All the experiments were performed in triplicate.

Centrifugation was performed at $3600 \mathrm{rpm}$ for 30 minutes at room temperature, and the samples visually heterogeneous were excluded afterwards. 
Stability against decomposition reactions such as hydrolysis was assessed through $\mathrm{pH}$ measurement by inserting the electrode directly into the sample.

Same technique was used to measure electrical conductivity, inserting the electrode directly into the sample to confirm the system type oil-in-water $(\mathrm{O} / \mathrm{W})$ and any tendency towards phase inversion.

Instabilities or liquid crystals were checked by inserting a sample droplet of each sample on the measuring prism surface and obtaining their respective refractive index.

\section{Stability Study}

The heating-cooling cycle was used to obtain the thermodynamic stability assessment. Two groups of samples were preliminarily subjected to alternating cycles of $5 \pm 1^{\circ} \mathrm{C}$ and $45 \pm 1^{\circ} \mathrm{C}$ for 24 hours each, during 14 days. The stable formulations at this point followed to accelerate stability test, once extreme conditions allow us to probe their long-term stability. Three groups of colloidal samples were submitted at temperatures of $45 \pm 1^{\circ} \mathrm{C}$, $25 \pm 1^{\circ} \mathrm{C}$ and $5 \pm 1^{\circ} \mathrm{C}$ for 90 days. Every 30 days, the formulations were maintained at room temperature for 24 hours to measure their physicochemical properties. The stability studies were performed in triplicate.

\section{Rheological Characterization}

The rheological parameters were determined by Modular Compact Rheometer - MCR 102 (Anton Paar ${ }^{\circledR}$, Germany). In all trials, $600 \mu \mathrm{L}$ of each formulation were placed on the surface of the reading plate. Data were taken with continuous control of the gap in $0.099 \mathrm{~mm}$. The measuring cell was a CP 50 and precise temperature control was achieved. Acquired data were treated using the Rheoplus V3.61 software.

The flow and viscosity curves were displayed using established parameters considering the control of shear stress $(\tau)$ in the $0-5 \mathrm{~Pa}$ range for the upsweep and 5-0Pa for the curve downward. These measurements were performed under isothermal conditions at $25^{\circ} \mathrm{C}$, comprising 75 readings for each analysis.

\section{Dynamic Light Scattering (DLS)}

Dynamic light scattering (DLS) was used to measure the mean particle size at $25^{\circ} \mathrm{C}$ through a Malvern Zetasizer Nano ZS (Malvern®, United Kingdom) 632.8nm excitation. Colloidal suspension samples (in triplicate) were prepared from a 10:1000 dilution of each formulation.

\section{RESULTS AND DISCUSSION}

In this investigation, it was developed a liquid $\mathrm{ME}$ formulation from Brazil nut oil as vehicle for LMS through diagrams that demonstrated linear viscosity in a Newtonian profile. It was classified as oil-in-water, had physicochemical stability and properties suitable for biological application.

To obtain the surfactant-mixing ratio, the co-surfactant (BT) concentration was fixed as $10 \%$, and the amount of the surfactants SP and TW were calculated to achieve the required
HBL for the Brazil nut oil. The obtained surfactant fractions were 4.2 and 4.8 for SP and TW, respectively, resulting in a total mix relation of $4.2: 4.8: 1.0$.

The SP/TW/BT (4.2/4.8/1.0) surfactant mixture was added with Brazil nut oil and distilled water in proportions established by the diagram (Figure 2). These data resulted in regions with different equilibrium characteristics.

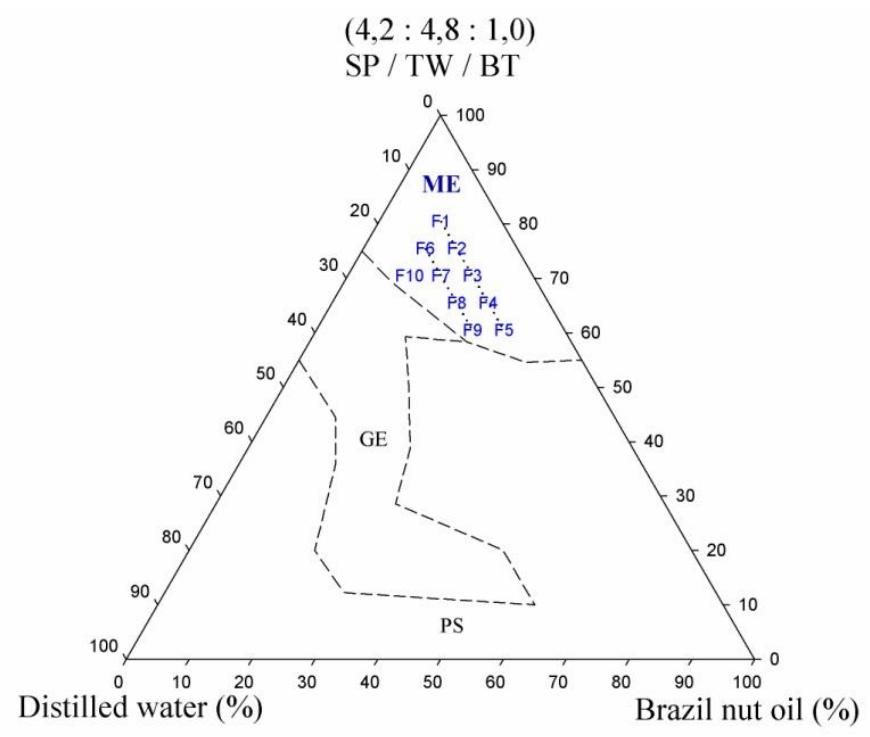

Fig. 2: Pseudoternary diagrams indicating region domains with selected (F1 to F10) microemulsion SP/TW/BT systems containing Brazil nut oil (Bertholletia excelsa H.B.K) and levamisole. Acronyms: Microemulsion (ME), Gel Emulsion $(G E)$, and Phase Separation (PS).

The stability of a ME depends on the interfacial interaction system established by the surfactant and co-surfactant between water and oil. So, the development of thermodynamically stable systems occurs by determining the appropriate ratio of surfactants (Lawrence and Rees 2012). Although the HLB is an empirical and representative value of the content of hydrophilic and lipophilic properties of the surfactant, it was shown to effectively allow the preparation of a large area of $\mathrm{ME}$, an agreement with literature (Lin 1970; Wu et al., 2001; Zhang and Que 2008). The proper adjustment of the HLB allows thermodynamically stable systems to have a smaller increase in the core and lower particle sizes (Housaindokht and Pour 2012). In the present study, the HLB technique was used to produce diagrams with large areas of stable systems.

The analysis of phase behavior allowed classifying three different regions: gelling emulsion (GE), $\mathrm{ME}$, and phase separation (PS). As well as indicated that a large range of surfactant compositions produced stable systems. However, when the surfactant domain concentration was below 55\%, some instability and phase separation were observed, indicating that at lower surfactant concentrations there could not be a balance between high proportions of aqueous and oily phases (Figure 2). It confirms that the Brazil nut oil is capable of forming large ranges 
of translucent systems. Several works have reported translucent formulation with capric/caprylic acid triglycerides (Ribeiro et al., 2015; Cotrim et al., 2016) and Babassu oil (Pessoa et al., 2014; Lanes et al., 2016), but none containing Brazil nut oil.

It is notable that phase diagrams can be employed to investigate the phase behavior of micro and Nanoemulsion systems, aiming to select translucent systems from other present structures, but unfortunately do not guarantee the stability of such systems, requiring further tests (Fryd and Mason 2012; Ribeiro $e t$ al., 2016).

Stability studies were performed in pre-selected stable formulations containing LMS, labeled F1 to F10. The results of the physicochemical analyses, attained before and after submitting samples to temperature variations, are listed in Table 1. Before thermal treatment, samples were submitted to centrifuge at 3600 $\mathrm{rpm}$ for 30 minutes, $25^{\circ} \mathrm{C}$. Then, it was observed that majority of the samples presented a visually normal $(\mathrm{N})$ behavior, remaining translucent after the stability test, what indicates high stability. The samples F5, F8 and F9 showed phase separation (PS) and were therefore eliminated.

All of the formulations were classified as $\mathrm{O} / \mathrm{W}$ for their electrical conductivity values above that of distilled water $(>1.3$ $\left.\mu \mathrm{S} . \mathrm{cm}^{-1}\right)$. Additionally, the refraction values remained around 1.44 and 1.46 , demonstrating constancy during the entire trials. This refractive index obtained before and after the stability tests indicates isotropic nature of the formulations (Ghosh et al., 2006). Although F3 and F10 did not present significant modifications in values of $\mathrm{pH}$, refraction and conductivity, they became opalescent during the cycles of temperature, being eliminated of the posterior tests. Afterwards, formulations F1, F2, F4, F6, and F7 containing LMS were submitted to accelerated stability studies.

Data attained from LMS loading samples submitted to heating-cooling temperature cycles (accelerated stability study) before starting (0), after 30, 60 and 90 days, are listed in Table 2 and Figure 3. As seen in Table 2, there was no meaningful change in the refractive index of all formulations over the 90 days of study under different temperatures. However, it was perceived with the time and hot temperature $\left(45^{\circ} \mathrm{C}\right)$ that variations in values of $\mathrm{pH}$ turned the formulations into more acid, likely to mean oil oxidation, once decomposition of LMS is increased by alkali $\mathrm{pH}$ range (Chiadmi et al., 2005).Still for the formulations under heat, the conductivity did not show considerable change during the accelerated stability study; therefore the maintenance of the systems $\mathrm{O} / \mathrm{W}$ was observed for all formulations, regardless of the temperature. The formulations under cooling and room temperature had their conductivity decreased in 60 days of study, reaching constancy afterwards (Figure 3). Therefore, although physicochemical variations might be noticed, formulations displayed visual homogeneity being translucent throughout the study time.

According to literature, these all characteristics confirm a stable nanostructured system achieved (Pratap et al., 2012). The long term stability presented by the synthesized MEs may be associated to their reduced size, low interfacial tension and possibly be subject of Brownian motion and no gravity (Solans et al., 2005; Fernandes et al., 2014).

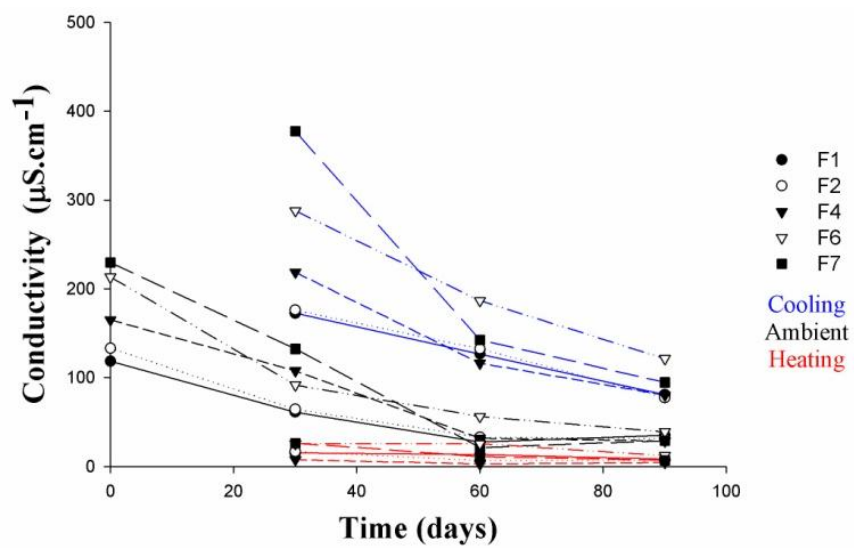

Fig. 3: Conductivity assay in accelerated stability study of microemulsion containing Brazil nut oil (Bertholletia excelsa H.B.K) and levamisole.

Attaining the flow and viscosity curves, as a function of shear rate, performed rheological characterization. Initially, flow curves of the stable LMS incorporated in ME formulations (F1, F2, F4, F6 andF7) we measured (Figure4). It is observed that for all formulation, the flow curves began at the origin and exhibited linear ascending, and descending behavior, indicating that these formulations behave as Newtonian fluids.

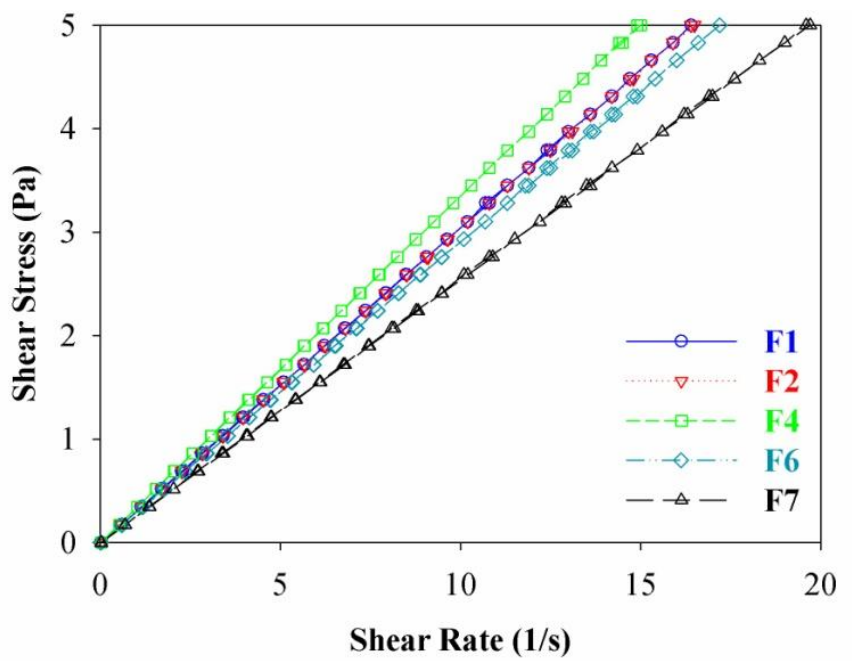

Fig. 4: Flow curves of microemulsion formulations containing Brazil nut oil (Bertholletia excelsa H.B.K) and levamisole at $25^{\circ} \mathrm{C}$.

In addition, viscosity curves as a function of shear rate are displayed in Figure 5. It was observed that the viscosity values did not change as the shear rate increased, with values between 0.25 and $0.35 \mathrm{~Pa}$ s. This ability to maintain the viscosity and Newtonian profile constant according to the shear rate in ME systems, allied to stability studies, keep the indicative of a ME physical stability.

Rheological properties of emulsions depend on their type, shape, density and number of components, as well as the interaction among them (Fryd and Mason 2012). Thus, 
microstructure changes influence the system rheology (Acharya and Hartley 2012). As for instance, liquid and translucent emulsions with long-term stability and appropriate for different applications generally exhibit Newtonian behavior with constant viscosity for a wide range of shear rate (Rojas et al., 2009; Acharya and Hartley 2012; Ribeiro et al., 2015; Cotrim et al., 2016). According to the literature, viscosity is largely influenced by modified-release systems associated with change of temperature (Chaud et al., 2014; França et al., 2014). In this report, the prepared formulations of Brazil nut oil and LMS presented Newtonian profile and no change in the hysteresis area.

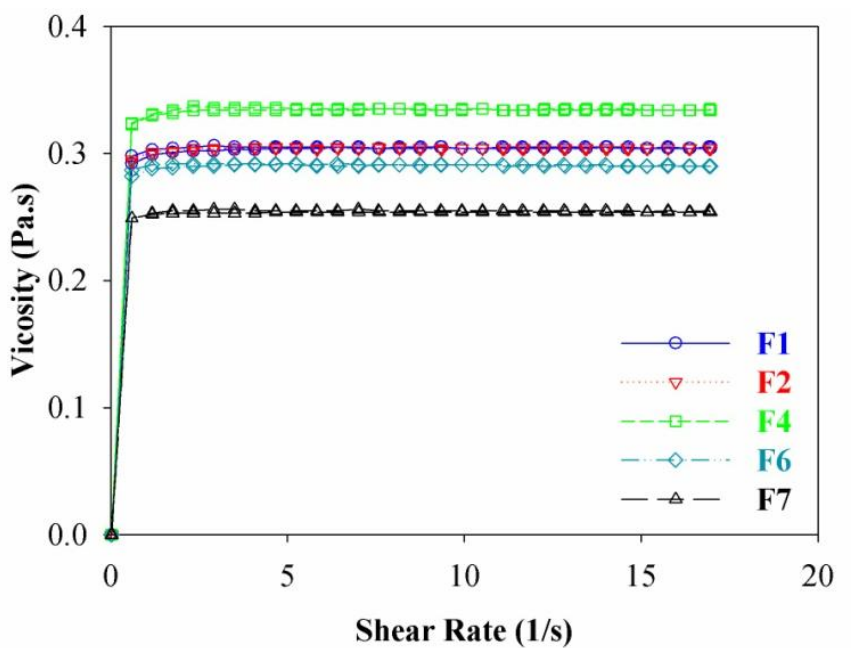

Fig. 5: Viscosity curves of microemulsion formulations containing Brazil nut oil (Bertholletia excelsa H.B.K) and levamisole at $25^{\circ} \mathrm{C}$.

Light scattering is a routine technique to determine the diameter of the ME internal phase (Kreilgaard 2002). Droplet size analysis and particle size distribution, attained by the DLS technique for formulations F1, F2, F4, F6 and F7, are displayed in Figure 6. It is observed that LMS loaded samples present nanostructure sizes and thin distribution.
Our findings demonstrate that the formulations containing Brazil nut oil and LMS presented variations regarding the components proportion in the formulations. The F1, F2, F4, F6, and F7 indicated average hydrodynamic diameter of 64.62; $49.73 ; 33.35 ; 104.55$ and $122.18 \mathrm{~nm}$, respectively.

Literature shows the diameters of the structures to be dependent on the surfactant ratio and oil phase of ME (Formariz et al., 2005), differently than nanoemulsions that also depend on the preparation process, specially on the type of mixing/blend (Ghosh et al., 2012). It was observed the formation of Nano scale structures with decreased hydrodynamic diameter when the surfactant proportion predominates over the oil phase (Aboofazeli et al., 2000; Tadros et al., 2004; Lawrence and Rees 2012). These results collaborate with the data of the systems developed, and indicate that the increase of Brazil nut oil concentration promoted a tendency to reduce the hydrodynamic diameter in specific proportions of aqueous phase $(10 \%)$.

This Nano scale structure of ME containing Brazil nut oil (Bertholletia excelsa H.B.K) and LMS allows it to be suitable for oral, parenteral, pulmonary, or ocular administration. In spite of the fact that its potential for topical use has not been neglected, more viscous systems are preferred for this type of application (Talegaonkar et al., 2008). Yet, microemulsions are easy to administer and can provide ideal characteristics for the release of oral or parenteral drugs and vaccines (Bagwe et al., 2001; Aguiar et al., 2002). This type of release system can improve therapeutic efficacy and therefore reduce drug and carrier volume in the formulation to minimize toxic effects and trigger immunomodulatory responses of LMS (Cui et al., 2003; Zhang et al., 2009). More studies should be conducted to verify the potential of this formulation as an adjuvant for drug delivery. According to the attained physicochemical characteristics, from all the stable formulations, F4 has been selected to conduct drug delivery and biological assays.

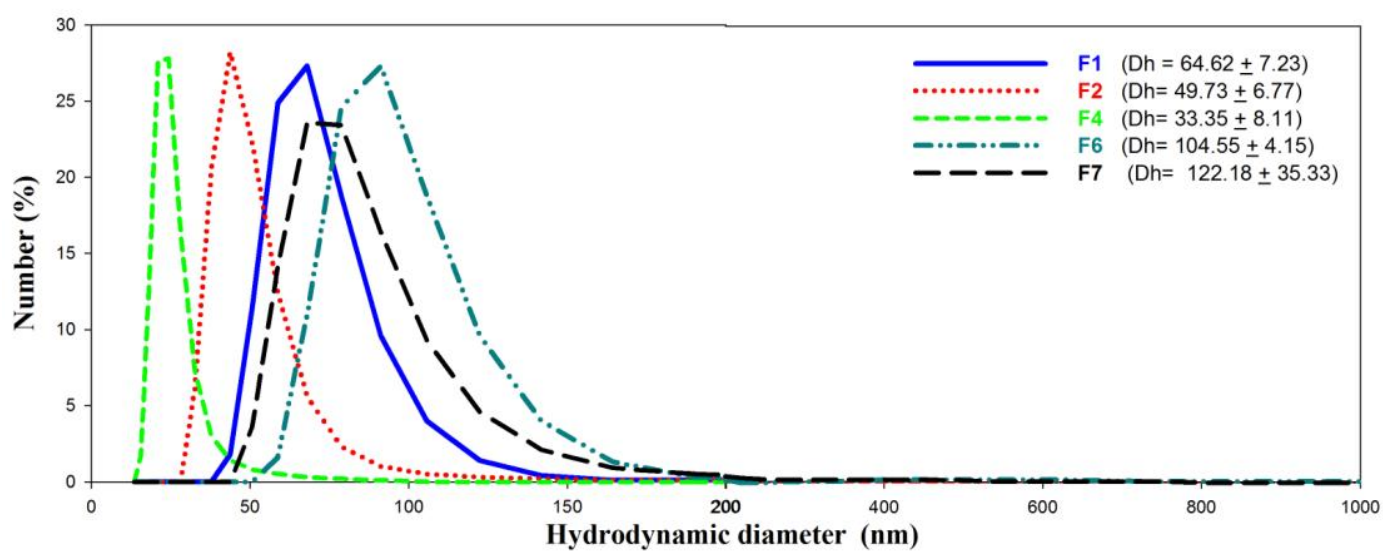

Fig. 6: Hydrodynamic diameter of microemulsion formulations containing Brazil nut oil (Bertholletia excelsa H.B.K) and levamisole. Acronyms: Hydrodynamic diameter $(D h)$. 
Table 1: Physicochemical parameters obtained in preliminary stability of microemulsion containing Brazil nut oil (Bertholletia excelsa H.B.K) and levamisole.

\begin{tabular}{|c|c|c|c|c|c|c|c|c|c|}
\hline \multirow{2}{*}{ Formulation } & \multirow{2}{*}{ Centrifugation } & \multicolumn{2}{|c|}{ Aspect } & \multicolumn{2}{|c|}{ Refractive Index } & \multicolumn{2}{|c|}{ Conductivity ( $\mu$ S.cm-1) } & \multicolumn{2}{|c|}{ pH } \\
\hline & & Before & After & Before & After & Before & After & Before & After \\
\hline F1 & $\mathrm{N}$ & TL & TL & 1.4521 & 1.4493 & 510.10 & 647.50 & 4.92 & 4.47 \\
\hline $\mathrm{F} 2$ & $\mathrm{~N}$ & TL & TL & 1.4600 & 1.4586 & 158.80 & 204.90 & 5.01 & 4.31 \\
\hline $\mathrm{F} 3$ & $\mathrm{~N}$ & TL & TL & 1.4614 & 1.4603 & 193.50 & 241.80 & 4.56 & 3.93 \\
\hline $\mathrm{F} 4$ & $\mathrm{~N}$ & TL & TL & 1.4611 & 1.4598 & 234.20 & 293.60 & 4.75 & 4.13 \\
\hline F5 & PS & - & - & - & - & - & - & - & - \\
\hline F6 & $\mathrm{N}$ & TL & TL & 1.4554 & 1.4550 & 294.40 & 362.70 & 4.97 & 4.27 \\
\hline F7 & $\mathrm{N}$ & TL & $\mathrm{TL}$ & 1.4560 & 1.4540 & 377.60 & 434.90 & 4.95 & 4.11 \\
\hline $\mathrm{F} 8$ & PS & - & - & - & - & - & - & - & - \\
\hline F9 & PS & - & - & - & - & - & - & - & - \\
\hline F10 & $\mathrm{N}$ & TL & TL & 1.4608 & 1.4611 & 178.80 & 212.50 & 4.52 & 3.97 \\
\hline
\end{tabular}

$\mathrm{N}=$ Normal; PS = Phase separation; TL $=$ Translucent liquid.

Table 2: Physicochemical parameters obtained in accelerated stability study of microemulsion containing Brazil nut oil (Bertholletia excelsa H.B.K) and levamisole.

\begin{tabular}{|c|c|c|c|c|c|c|c|}
\hline \multirow{2}{*}{ Day } & \multirow{2}{*}{ Formulation } & \multicolumn{3}{|c|}{ Refraction } & \multicolumn{3}{|c|}{ pH } \\
\hline & & $5^{\circ} \mathrm{C}$ & $25^{\circ} \mathrm{C}$ & $45^{\circ} \mathrm{C}$ & $5^{\circ} \mathrm{C}$ & $25^{\circ} \mathrm{C}$ & $45^{\circ} \mathrm{C}$ \\
\hline \multirow{5}{*}{0} & F1 & - & $1.4586 \pm 2 \mathrm{e}-3$ & - & - & $4.82 \pm 0,21$ & - \\
\hline & $\mathrm{F} 2$ & - & $1.4608 \pm 1 \mathrm{e}-4$ & - & - & $4.92 \pm 0.12$ & - \\
\hline & $\mathrm{F} 4$ & - & $1.4613 \pm 3 \mathrm{e}-4$ & - & - & $4.99 \pm 0.19$ & - \\
\hline & F6 & - & $1.4558 \pm 6 \mathrm{e}-4$ & - & - & $5.02 \pm 0.04$ & - \\
\hline & F7 & - & $1.4552 \pm 1 \mathrm{e}-4$ & - & - & $5.02 \pm 0.03$ & - \\
\hline \multirow{5}{*}{30} & F1 & $1.4617 \pm 9 \mathrm{e}-4$ & $1.4702 \pm 8 \mathrm{e}-4$ & $1.4745 \pm 3 e-3$ & $5.10 \pm 0.07$ & $3.97 \pm 0.06$ & $3.90 \pm 0.33$ \\
\hline & $\mathrm{F} 2$ & $1.4625 \pm 7 \mathrm{e}-4$ & $1.4698 \pm 6 \mathrm{e}-4$ & $1.4756 \pm 6 \mathrm{e}-4$ & $4.96 \pm 0.10$ & $3.69 \pm 0.14$ & $3.25 \pm 0.25$ \\
\hline & $\mathrm{F} 4$ & $1.4645 \pm 7 e-4$ & $1.4662 \pm 2 \mathrm{e}-3$ & $1.4768 \pm 9 \mathrm{e}-4$ & $4.68 \pm 0.19$ & $3.26 \pm 0.35$ & $2.71 \pm 0.51$ \\
\hline & F6 & $1.4568 \pm 2 \mathrm{e}-3$ & $1.4668 \pm 3 \mathrm{e}-4$ & $1.4774 \pm 1 \mathrm{e}-4$ & $5.09 \pm 0.19$ & $3.32 \pm 0.12$ & $2.90 \pm 0.11$ \\
\hline & F7 & $1.4583 \pm 3 e-4$ & $1.4676 \pm 6 \mathrm{e}-3$ & $1.4777 \pm 4 \mathrm{e}-4$ & $5.00 \pm 0.19$ & $3.80 \pm 0.05$ & $2.72 \pm 0.39$ \\
\hline \multirow{5}{*}{60} & F1 & $1.4651 \pm 2 \mathrm{e}-4$ & $1.4746 \pm 9 \mathrm{e}-4$ & $1.4749 \pm 3 e-4$ & $5.20 \pm 0.05$ & $3.26 \pm 0.18$ & $3.82 \pm 0.22$ \\
\hline & $\mathrm{F} 2$ & $1.4657 \pm 2 \mathrm{e}-3$ & $1.4747 \pm 1 \mathrm{e}-3$ & $1.4754 \pm 1 \mathrm{e}-3$ & $4.78 \pm 0.09$ & $3.08 \pm 0.52$ & $3.36 \pm 0.21$ \\
\hline & $\mathrm{F} 4$ & $1.4652 \pm 2 \mathrm{e}-3$ & $1.4746 \pm 3 \mathrm{e}-4$ & $1.4755 \pm 2 \mathrm{e}-4$ & $4.16 \pm 0.43$ & $2.99 \pm 0.05$ & $2.71 \pm 0.05$ \\
\hline & F6 & $1.4623 \pm 2 \mathrm{e}-3$ & $1.4739 \pm 2 \mathrm{e}-3$ & $1.4767 \pm 2 \mathrm{e}-3$ & $4.64 \pm 0.12$ & $2.97 \pm 0.18$ & $2.61 \pm 0.04$ \\
\hline & F7 & $1.4629 \pm 1 \mathrm{e}-3$ & $1.4760 \pm 6 \mathrm{e}-4$ & $1.4746 \pm 1 \mathrm{e}-4$ & $4.17 \pm 0.09$ & $2.75 \pm 0.31$ & $2.77 \pm 0.35$ \\
\hline \multirow{5}{*}{90} & $\mathrm{~F} 1$ & $1.4648 \pm 9 \mathrm{e}-4$ & $1.4725 \pm 6 \mathrm{e}-4$ & $1.4754 \pm 6 \mathrm{e}-4$ & $4.28 \pm 0.09$ & $3.29 \pm 0.17$ & $3.44 \pm 0.16$ \\
\hline & $\mathrm{F} 2$ & $1.4654 \pm 3 e-4$ & $1.4727 \pm 5 \mathrm{e}-4$ & $1.4754 \pm 8 \mathrm{e}-4$ & $4.35 \pm 0.18$ & $3.02 \pm 0.10$ & $2.72 \pm 0.07$ \\
\hline & $\mathrm{F} 4$ & $1.4666 \pm 8 \mathrm{e}-4$ & $1.4730 \pm 6 \mathrm{e}-4$ & $1.4757 \pm 7 \mathrm{e}-4$ & $3.96 \pm 0.17$ & $2.80 \pm 0.15$ & $2.42 \pm 0.27$ \\
\hline & F6 & $1.4649 \pm 2 \mathrm{e}-3$ & $1.4734 \pm 2 \mathrm{e}-4$ & $1.4754 \pm 8 \mathrm{e}-4$ & $4.42 \pm 0.14$ & $2.74 \pm 0.34$ & $2.24 \pm 0.21$ \\
\hline & F7 & $1.4659 \pm 1 \mathrm{e}-3$ & $1.4742 \pm 4 \mathrm{e}-4$ & $1.4749 \pm 8 \mathrm{e}-4$ & $4.59 \pm 0.23$ & $2.47 \pm 0.60$ & $2.36 \pm 0.33$ \\
\hline
\end{tabular}

\section{CONCLUSION}

In the present collaboration, a stable $\mathrm{O} / \mathrm{W}$ micro emulsion system containing Brazil nut oil and LMS was developed and different formulations were tested. The F4 (water 9.4\%; Brazil nut oil 23.5\%; SP 25.7\%; TW 29.4\%; BT 6.1\%) presented the best parameters as stability and ME. It showed the best standing $\mathrm{pH}$, conductivity, and refractive index along the study, representing satisfactory stability under long-term stress conditions. Its particle size is classified as ME $(33.35 \mathrm{~nm})$, and rheological parameters confirm a Newtonian behavior, with constant viscosity. In addition, Brazil nut oil is a natural product, easy to obtain in Brazil, and can be added to the diet, so may be an choice for future therapy applications, in particular for infectious and immunological diseases.

The Brazil nut oil ME system is a new alternative for possible use in drug delivery vehicle and as an adjuvant. A promising ME system to carry LMS in an upgraded pharmaceutical form opens new perspectives to improve the efficiency of this drug therapy, such as in parasitic diseases and cancer.

Financial support and sponsorship: Nil.

Conflict of Interests: There are no conflicts of interest.

\section{REFERENCES}

Aboofazeli R, Barlow DJ, Lawrence MJ.Particle size analysis of concentrated phospholipid microemulsions I. Total intensity light scattering. Am. Assoc. Pharm. Sci. 2000; 2: 1-13.

Acharya DP, Hartley PG. Progress in microemulsion characterization. Curr. Opin. Colloid Interface Sci. 2012;17:274-80.

Aguiar JC, Hedstrom RC, Rogers WO, Charoenvit Y, Sacci JB, Lanar DE, MajamVF, Stout RR, Hoffman SL. Enhancement of the immune response in rabbits to a malaria DNA vaccine by immunization with a needle-free jet device.Vaccine.2002;20:275-80.

Ansari SH, Islam F, Sameen M. Influence of nanotechnology on herbal drugs : A Review. J. Adv. Pharm. Technol. e Res. 2012;3:142-6.

Bagwe RP, Kanicky BJ, Palla PK, Patanjali PK, Shah DO. Improved drug delivery using microemulsions: rationale, recent progress and new horizons. Crit. Rev. Ther. Drug Carrier Syst. 2001;18:77-140. 
Bonifácio BV, da Silva PB, Ramos, MAS, Negri, KMS, Bauab, TM, Chorilli M, Nanotechnology-based drug delivery systems and herbal medicines: A review. Int. J. Nanomedicine. 2014;9:1-15.

Chaud NGA, França EL, Ribeiro EB, Pessoa R, Lanes PKD, Honorio-França AC. Desenvolvimento e caracterização de um neomaterial a base de microemulsão como veículo de Lippiasidoides. Sodebras. 2014;9:31-8.

Chiadmi F, Iyer A, Cisternino S, Toledano A, Schlatter J, Ratiney R, et al., Stability of levamisole oral solutions prepared from tablets and powder. J. Pharm. Pharm. Sci. 2005;8:322-5.

Cotrim AC de M, Honorio-frança AC, França EL. Rheology analysis can be added in thermal stability test for design microemulsion materials. Biointerface Res. Appl. Chem. 2016;6:1128-36.

Cui Z, Baizer L, Mumper RJ. Intradermal immunization with novel plasmid DNA-coated nanoparticles via a needle-free injection device.J. Biotechnol. 2003;102:105-15.

Fernandes CP, Almeida FB de, Silveira AN, Gonzalez MS, Mello CB, Feder D, Apolinário RS, Santos MG, Carvalho JCT, Tietbohl LAC, Falcão DQ. Development of an insecticidal nanoemulsion with Manilkarasubsericea (Sapotaceae) extract.J. Nanobiotechnology. 2014;12:1-9.

Ferreira E de S, Silveira C da S, Lucien VG, Amaral AS. Caracterização físico-química da amêndoa, torta e composição dos ácidos graxos majoritários do óleo bruto da castanha-do-Brasil (Bertholletia excelsa H.B.K). Alim Nutr. 2006;17:203-8.

Formariz TP, Cristina M, Urban C, Antônio A, Palmira M, Gremião D, Oliveira AG. Microemulsões e fases líquidas cristalinas como sistemas de liberação de fármacos. Rev. Bras. Ciências Farm. 2005;41:301-13.

França EL, Ribeiro EB, Scherer EF, Cantarini DG, Pessôa RS, França FL, Honorio-frança AC. Effects of Momordicacharantia L. on the Blood Rheological Properties in Diabetic Patients. Biomed Res. Int. 2014;2014:1-8.

Fryd MM, Mason TG. Advanced Nanoemulsions.Annu. Rev. Phys. Chem. 2012;63:493-518.

Ghosh PK, Majithiya RJ, Umrethia ML, Murthy RSR. Design and development of microemulsion drug delivery system of acyclovir for improvement of oral bioavailability. AAPS PharmSciTech.2006;7:77.

Ghosh V, Mukherjee A, Chandrasekaran N. Ultrasonic emulsification of food-grade nanoemulsion formulation and evaluation of its bactericidal activity. Ultrason. Sonochem. 2012;20:338-44.

Gonçalves AM, Fernandes KG, Ramos LA, Cavalheiro ETG, Nóbrega JA. Determination and Fractionation of Barium in Brazil Nuts.J. Braz. Chem. Soc. 2009;20:760-9.

Hafner A, Lovric J, Lakos GP, Pepic I. Nanotherapeutics in the EU: an overview on current state and future directions. Int. J. Nanomedicine. 2014;9:1005-23.

Housaindokht MR, Pour AN. Study the effect of HLB of surfactant on particle size distribution of hematite nanoparticles prepared via the reverse microemulsion. Solid State Sci. 2012;14:622-5.

Hu S, Tsai C, Liao C, Liu D, Chen S. Controlled Rupture of Magnetic Polyelectrolyte Microcapsules for Drug Delivery. Langmuir. 2008;24:11811-8

Kesarwani K, Gupta R. Bioavailability enhancers of herbal origin : A n overview. Asian J. Pharm. Sci. 2013;3:253-66.

Kluczkovski AM, Martins M, Mundim SM, Simões H, Nascimento KS, Marinho HA. Properties of Brazil nuts: A review. African J. Biotechnol.2015;14:642-8.

Kreilgaard M. Influence of microemulsion on cutaneos drugs delivery. Adv. DrugDeliv. Rev. 2002;54:77-98.

Lanes PKD, Ribeiro EB, Chaud NGA, Pessoa RS, França EL, Honorio-frança AC. Effects of microemulsion incorporated with OrbignyamartianaRodr on the functional activity of blood phagocytes. Wulfenia J. 2016;1:214-36.
Lawrence MJ, Rees GD. Microemulsion-based media as novel drug delivery systems. Adv. Drug Deliv.Rev. 2012;64:175-93.

Lin TJ. Surfactent Location and Required HLB. J. Soc. Cosmet. Chem. 1970;21:365-75.

Pessoa RS, França EL, Ribeiro EB, Abud NG, Honorio- AC. Microemulsion of babassu oil as a natural product to improve human immune system function. Drug Des. Devel. Ther. 2014;9:21-31.

Pezzini BR, Antônio M, Silva S, Ferraz HG. Formas farmacêuticas sólidas orais de liberação prolongada: sistemas monolíticos e multiparticulados. Rev. Bras. Ciências Farm. 2007;43:491-502.

Pratap SB, Brajesh K, Jain SK, Kausar S. Development and Characterization of A Nanoemulsion Gel formulation for Transdermal delivery of Carvedilol. Int. J. Drug Dev. Res. 2012;4:151-61.

Ribeiro EB, Honório-França AC, França EL, Soler MAG. Design and Development of Nanoemulsion Systems Containing Interferon Gamma. ProteinPept. Lett. 2016;23:626-38.

Ribeiro EB, Kelly P, Lanes D, Galdeano N, Chaud A, Pessoa RS, Honorio-frança AC, França EL. Microemulsions with Levamisole Delivery Systems as Novel Immunomodulating Agents with Potential for Amebiasis Therapies. Sci. Adv. Mater. 2015;7:15-27.

Rojas O, Koetz J, Kosmella S, Tiersch B, Wacker P, Kramer M. Structural studies of ionic liquid-modified microemulsions. J. Colloid Interface Sci. 2009;333:782-90.

Santos OV dos, Correa NCF, Lannes SC da S. Caracterização física, físico-química, microbiológica e micotoxicológica da Castanha-doBrasil (Bertholletia excelsaH.B.K). Iluminart.2011;48-59.

Shaji J, Jadhav D. Newer ApprochesToSelf Emulsifying Drug Delivery System. Int. J. Pharm. Pharm. Sci. 2010;2:37-42.

Silva RF da, Ascheri JLR, Souza JML de. Influência do processo de Beneficiamento Qualidade de Amêndoas de Castanha-doBrasil. Ciência e Agrotecnologia. 2010;34:445-50.

Solans C, Izquierdo P, Nolla J, Azemar N, Garcia-Celma MJ. Nano-emulsions.Curr.Opin. Colloid Interface Sci. 2005;10:102-10.

Tadros T, Izquierdo P, Esquena J, Solans C. Formation and stability of nano-emulsions. Adv. Colloid Interface Sci. 2004:108109:303-18

Talegaonkar S, Azeem A, Ahmad FJ, Khar RK, Pathan SA, Khan ZI. Microemulsions: A Novel Approach to Enhanced Drug Delivery. Recent Patents Drug Deliv.Formultion. 2008;2:238-57.

$\mathrm{Wu} \mathrm{H}$, Ramachandran C, Weiner ND, Roessler BJ.Topical transport of hydrophilic compounds using water-in-oil nanoemulsions.Int. J. Pharm. 2001;220:63-75.

Zhang L, Que G. Influence of the HLB parameter of surfactants on the dispersion properties of brine in residue. Colloids Surfaces A Physicochem. Eng. Asp.2008;320:111-4.

Zhang W, Du X, Zhao G, Jin H, Kang Y, Xiao C, Liu M, Wang B. Levamisole is a potential facilitator for the activation of Th1 responses of the subunit HBV vaccination. Vaccine.2009;27:4938-46.

How to cite this article:

Gustmann PC, Cotrim ACM, Pires EM, Andrighetti CR, Valladão DMS, Ribeiro EB. Development of Brazil nut oil microemulsion as vehicle for Levamisole. J App Pharm Sci, 2017; 7 (08): 092-098. 